\title{
Construindo competências para ação educativa da enfermeira na atenção básica*
}

\author{
BUILDING SKILLS FOR THE NURSE'S EDUCATIONAL ACTIONS IN PRIMARY HEALTH CARE \\ CONSTRUYENDO COMPETENCIAS PARA LA ACCIÓN EDUCATIVADE \\ LAENFERMERA EN LAATENCIÓN BÁSICA
}

Valéria Marli Leonello', Maria Amélia de Campos Oliveira²

\section{RESUMO}

Trata-se de um estudo qualitativo com o objetivo de descrever a metodologia do processo de construção coletiva de um perfil de competências para a ação educativa da enfermeira. A categoria conceitual utilizada foi a competência, ancorada nas concepções de trabalho em saúde e saber operante. Foram coletados discursos de docentes e estudantes do curso de bacharelado em enfermagem da EEUSP; enfermeiras, gestores e usuários dos serviços de saúde vinculados à Universidade de São Paulo, analisados com a técnica de análise de discurso. Houve similaridades em relação a conhecimentos, habilidades e atitudes necessárias ao desenvolvimento de práticas educativas mais dialógicas e participativas. Foi possível a construção de um perfil de competências para a ação educativa da enfermeira, numa perspectiva coletiva e das necessidades de saúde.

\section{DESCRITORES}

Educação em enfermagem. Educação baseada em competências.

Competência profissional. Cuidados de enfermagem.

\section{ABSTRACT}

This is a study to review the methodological process developed to built a profile of competencies required for nurse's educational actions. It was a qualitative research, in the historical and dialectical materialism, that used competence as the conceptual category, anchored in the conceptions of work in health and operating knowledge. The subjects were teachers and students of the School of Nursing of University of Sao Paulo (USP), Brazil; nurses, managers and patients of health services connected to USP. The speech analysis technique was used to analyze the speeches. All groups addressed contained similarities related to knowledge, skills and attitudes required to the development of more dialogical and participative educational practices. The methodological approach described enable the construction of a profile of competencies related to nurse's educational actions, in a collective perspective, closer to the population's health needs.

\section{KEY WORDS}

Education, nursing.

Competency-based education.

Professional competencie.

Nursing care.

\section{RESUMEN}

Tratase de un estudio cualitativo para construcción de un perfil de competencias para la acción educativa de la enfermera. Utilizó el materialismo histórico y dialéctico, y como categoría conceptual la competencia, basada en las concepciones de trabajo en salud y saber operativo. Participaron docentes y estudiantes de bachillerato en enfermería de la EEUSP, enfermeras, gestores y usuarios de los servicios de salud vinculados a la Universidad de São Paulo. Se utilizó la técnica de análisis de discurso. Todos presentaron similitudes en relación a conocimientos, habilidades y actitudes necesarias para el desarrollo de prácticas educativas más dialogantes y participativas. La metodología posibilitó la construcción de un perfil de competencias para la acción educativa de la enfermera, en una perspectiva colectiva y más próxima a las necesidades de salud.

\author{
Extraído da \\ dissertação \\ "Competências para \\ ação educativa da \\ enfermeira: uma \\ interface entre ensino \\ e assistência de \\ enfermagem", Escola \\ de Enfermagem, \\ Universidade de São \\ Paulo, 2007. \\ ${ }^{1}$ Enfermeira. Mestre \\ em Enfermagem pelo \\ Programa de Pós- \\ Graduação Enfer- \\ magem em Saúde \\ Coletiva da Escola \\ de Enfermagem, \\ Universidade de São \\ Paulo (EEUSP). São \\ Paulo, SP, Brasil. \\ valeria.leonello@ \\ gmail.com \\ 2 Enfermeira. Livre- \\ docente. Professora \\ Assistente do Depar- \\ tamento de Enferma- \\ gem em Saúde \\ Coletiva da Escola \\ de Enfermagem, \\ Universidade de São \\ Paulo (EEUSP). São \\ Paulo, SP, Brasil. \\ macampos@usp.br
}

\section{DESCRIPTORES}

Educación en enfermería.

Educación basada en competencias.

Competencia profesional.

Atención de enfermería. 


\section{INTRODUÇÃO}

Historicamente, a prática educativa realizada por enfermeiras no cotidiano da assistência tem enfatizado a transmissão de informações e a mudança de comportamentos dos indivíduos. Vincula-se a um modelo de atenção à saúde voltado para a doença, com ênfase no conhecimento técnico-científico especializado.

Produto da fragmentação das ações de saúde, tais práticas educativas apresentam caráter autoritário e coercitivo ${ }^{(1-}$ 2) e têm se mostrado ineficientes para atender as necessidades de cuidado à saúde de indivíduos, famílias e grupos sociais, pois não levam em conta a determinação social do processo saúde-doença e não estão orientadas para promover a participação dos sujeitos sociais no enfrentamento de suas necessidades e seus problemas de saúde ${ }^{(3)}$.

Como conseqüência, observa-se um grande distanciamento entre os projetos educativos desenvolvidos pelas enfermeiras nos serviços de saúde e as necessidades de cuidado da população. As enfermeiras, por sua vez, queixam-se de dificuldades e de falta de competência para desenvolver práticas educativas mais dialógicas e participativas, como as defendidas pela Educação Popular ${ }^{(4-5)}$.

A formação inicial em enfermagem tem um papel essencial no desenvolvimento de competências para ação educativa. As Diretrizes Curriculares Nacionais (DCNs), em vigor desde 2001, reafirmam a necessidade e o dever das Instituições de Ensino Superior de formar profissionais de saúde para o SUS, com a finalidade de adequar a formação em saúde às necessidades de saúde da população brasileira ${ }^{(6)}$.

Com este desafio, realizou-se um estudo ${ }^{(7)}$ que teve como objetivo construir um perfil de competências para ação educativa da enfermeira, a partir da perspectiva de todos os sujeitos envolvidos no processo ensino-aprendizagem, cujo percurso metodológico será descrito a seguir, com ênfase no processo analítico dos dados empíricos.

\section{MÉTODO}

Estudo exploratório e qualitativo que teve como marco teórico-metodológico o materialismo histórico e dialético. Adotou como premissa a ação educativa em saúde na perspectiva da Educação Popular ${ }^{(4-5)}$ e Educação Popular em Saúde ${ }^{(1-3)}$. A categoria conceitual que orientou o conhecimento do objeto proposto foi a competência ${ }^{(8)}$, ancorada nas concepções de trabalho em saúde e saber operante ${ }^{(9)}$.

Na perspectiva adotada, desenvolver competências significa desenvolver diferentes atributos (conhecimentos, habilidades e atitudes) que combinados podem configurar possibilidades distintas de realizar com sucesso as atividades vinculadas a uma prática profissional. Segundo essa concepção, é na ação desenvolvida nos diferentes cenários em que se realiza uma determinada prática social que o estudante consegue articular esses conhecimentos, habilidades e valores pessoais para solucionar com eficácia uma série de situações. Portanto, a construção do perfil de competências desejado para uma determinada área profissional deve partir da investigação dos processos de trabalho e de todos os sujeitos neles envolvidos ${ }^{(8)}$.

Discutir desenvolvimento de competências na perspectiva da formação para o trabalho, em grande medida, significa formar para cidadania. Atento a esse aspecto, o Relatório da Comissão Internacional sobre Educação para o Século XXI, postulou quatro pilares da educação do futuro: saber conhecer, saber fazer, saber ser e saber conviver. Tais pilares são eixos norteadores de uma proposta de educação que visa a um projeto de vida em comum, incorporando conhecimentos e habilidades às atitudes pessoais e sociais ${ }^{(10)}$.

Saber conhecer refere-se ao domínio dos instrumentos da esfera cognitiva. Nessa esfera, o processo de aprendizagem nunca está acabado, devendo ser construído ao longo das experiências cotidianas dos sujeitos, pressupondo um aprender a aprender contínuo. O saber fazer não se restringe ao preparo para uma determinada tarefa, com o apoio de técnicas ou procedimentos. Implica a necessidade de articular e combinar o preparo técnico às aptidões pessoais e relacionais, que envolvem, entre outros aspectos, o trabalho em equipe, a iniciativa e a tomada de decisão frente às diferentes situações da prática profissional. O saber conviver representa o maior desafio da educação. A convivência depende da descoberta do outro como sujeito e da construção coletiva de projetos comuns, respeitando os valores de pluralismo, compreensão mútua e paz. Finalmente, o saber ser implica comprometimento e compromisso social do trabalhador em relação à sua realidade, reconhecendo-se como sujeito capaz de transformar e melhorar essa realidade.

No campo da saúde, especialmente no que se refere à formação profissional, os quatro pilares da educação permitem compreender que a construção de competências implica articular diferentes saberes para construção de uma prática profissional pautada não somente na aquisição e incorporação de conhecimentos e habilidades, mas também em atitudes pessoais e relacionais que visam à construção de um projeto comum para a transformação da realidade em saúde.

\section{Procedimentos metodológicos}

Os locais de estudo foram a Escola de Enfermagem da Universidade de São Paulo (EEUSP) e dois serviços de saúde vinculados à USP: o Hospital Universitário (HU) e o Centro de Saúde Escola Samuel Barnsley Pessoa do Butantã (CSE).

Participaram cinco grupos de sujeitos, sendo cinco docentes da EEUSP (grupo 1); cinco alunas concluintes do 
Bacharelado em Enfermagem da EEUSP (grupo 2); dez enfermeiras, sendo cinco de cada serviço mencionado (grupo 3); dois gestores, sendo um de cada serviço (grupo 4) e oito usuários, sendo cinco do HU e três do CSE, totalizando 30 participantes. As técnicas de abordagem utilizadas foram o grupo focal para docentes e alunos e a entrevista semiestruturada para enfermeiras, gestores e usuários.

\section{Análise dos dados}

Os dados foram submetidos ao método de análise de discurso $^{(11)}$. Os textos obtidos mediante a transcrição das falas foram decompostos em temas e figuras. Figuras são palavras ou expressões que existem no mundo real, enquanto que temas são palavras ou expressões que organizam e categorizam a realidade. Pesquisadoras enfermeiras ${ }^{(12)}$ que utilizaram esse tipo de análise em pesquisas na área de Enfermagem recomendam a leitura exaustiva do texto e sua recomposição em frases temáticas que, posteriormente, são sintetizadas em temas.
As frases temáticas resultantes do procedimento analítico foram organizadas segundo os quatro pilares da educação ${ }^{(10)}$ para cada grupo abordado. Por último, conhecimentos, habilidades e atitudes de todos os grupos foram articulados e recompostos em um quadro síntese das competências para a ação educativa da enfermeira.

O método dialético presume a realização de um movimento que é ao mesmo tempo analítico e sintético, pois os dados empíricos são primeiramente decompostos, facilitando sua captação e compreensão, e em seguida, recompostos, iluminados pelo referencial teórico utilizado.

\section{RESULTADOS}

A seguir são apresentados os quadros resultantes da recomposição das frases temáticas em conhecimentos (saber conhecer), habilidades (saber fazer) e atitudes (saber ser e conviver) para cada grupo abordado.

Quadro 1 - Conhecimentos, habilidades e atitudes para a ação educativa da enfermeira na perspectiva de docentes da EEUSP - São Paulo - 2007

\begin{tabular}{|c|c|c|c|}
\hline Saber conhecer & Saber fazer & Saber ser & Saber conviver \\
\hline $\begin{array}{c}\text { Ter conhecimento técnico } \\
\text { específico da profissão e } \\
\text { conhecimento das áreas } \\
\text { biológica e social }\end{array}$ & $\begin{array}{c}\text { Reconhecer a diversidade dos cenários de atuação } \\
\text { profissional } \\
\text { Relacionar o conhecimento com a prática } \\
\text { Usar o raciocínio clínico } \\
\text { Estabelecer estratégias de comunicação adequadas aos } \\
\text { usuários. } \\
\text { Desenvolver a escuta } \\
\text { Negociar com os usuários dos serviços possibilidades } \\
\text { de superação de sua condição de saúde } \\
\text { Saber integrar os processos de trabalho em } \\
\text { enfermagem } \\
\text { Reconhecer a amplitude e a processualidade da ação } \\
\text { educativa }\end{array}$ & $\begin{array}{c}\text { Reconhecer-se como agente } \\
\text { de transformação da } \\
\text { realidade } \\
\text { Assumir responsabilidade } \\
\text { sobre a própria } \\
\text { aprendizagem } \\
\text { Construir sua identidade } \\
\text { como pessoa e como } \\
\text { enfermeira } \\
\text { Perceber-se e compreender- } \\
\text { se como ser humano }\end{array}$ & $\begin{array}{c}\text { Relacionar-se com sujeitos e } \\
\text { grupos de diferentes } \\
\text { condições socioeconômicas } \\
\text { Reconhecer o outro } \\
\text { Dialogar com os parceiros de } \\
\text { trabalho } \\
\text { Reconhecer e respeitar a } \\
\text { autonomia dos usuários }\end{array}$ \\
\hline
\end{tabular}

As docentes enfatizaram as dimensões do saber ser e do saber conviver durante a formação inicial, sendo que as atitudes, tanto pessoais como relacionais, foram menos mencionadas que as habilidades. Os conhecimentos também foram pouco citados pelo grupo.

No grupo 2, constituído pelas alunas de enfermagem, nota-se predominância das habilidades e das atitudes relacionais. Os conhecimentos e atitudes pessoais foram pouco mencionados.
Todas as dimensões das competências foram significativamente mencionadas pelo grupo 3 , composto pelas enfermeiras dos serviços. Pode-se dizer que as atitudes relacionais foram as menos mencionadas, em comparação às demais.

O grupo 4, integrado pelos gestores, destacou as habilidades e as atitudes relacionais. A liderança e a coordenação da equipe apareceram fortemente, e foi feita menção à capacidade de relacionamento com os usuários dos serviços e com a equipe de saúde, gerenciando conflitos. Já a dimensão do saber ser foi a menos mencionada. 
Quadro 2 - Conhecimentos, habilidades e atitudes para a ação educativa da enfermeira na perspectiva de alunas da EEUSP - São Paulo - 2007

\begin{tabular}{|c|c|c|c|}
\hline Saber conhecer & Saber fazer & Saber ser & Saber conviver \\
\hline $\begin{array}{l}\text { Ter conhecimento técnico } \\
\text { específico da profissão } \\
\text { Ter conhecimento teórico } \\
\text { relacionado à psicologia } \\
\text { Ter conhecimento de } \\
\text { técnicas grupais }\end{array}$ & $\begin{array}{l}\text { Estabelecer estratégias de comunicação adequadas } \\
\text { aos usuários } \\
\text { Conhecer os sujeitos que irá abordar } \\
\text { Trabalhar com técnicas grupais } \\
\text { Partir das necessidades e do conhecimento dos } \\
\text { sujeitos } \\
\text { Negociar com os usuários dos serviços possibilidades } \\
\text { de superação de suas condições de saúde. } \\
\text { Fazer com que os usuários se reconheçam como } \\
\text { agentes de transformação de sua própria vida }\end{array}$ & $\begin{array}{c}\text { Reconhecer-se como } \\
\text { agente de transformação } \\
\text { da realidade }\end{array}$ & $\begin{array}{l}\begin{array}{l}\text { Respeitar e valorizar o conhecimento } \\
\text { dos sujeitos }\end{array} \\
\text { Compreender o modo de viver e de } \\
\text { trabalhar dos sujeitos } \\
\text { Identificar-se com os sujeitos } \\
\text { Reconhecer os sujeitos como agentes } \\
\text { de transformação de sua própria vida } \\
\text { Respeitar os valores culturais e a } \\
\text { autonomia dos sujeitos em relação a } \\
\text { suas vidas. }\end{array}$ \\
\hline
\end{tabular}

Quadro 3 - Conhecimentos, habilidades e atitudes para a ação educativa da enfermeira na perspectiva de enfermeiras do HU e CSE - São Paulo - 2007

\begin{tabular}{|c|c|c|c|}
\hline Saber conhecer & Saber fazer & Saber ser & Saber conviver \\
\hline $\begin{array}{c}\text { Reconhecer o cuidado com } \\
\text { um olhar ampliado } \\
\text { Ter conhecimento sobre o } \\
\text { serviço e os recursos que ele } \\
\text { oferece; a realidade da } \\
\text { população; o processo de } \\
\text { trabalho; os indicadores de } \\
\text { saúde e os perfis } \\
\text { epidemiológicos } \\
\text { Psicologia, Antropologia, } \\
\text { Anatomia,Fisiologia, } \\
\text { Patologia } \\
\text { Trabalho em equipe } \\
\text { Teorias de Cuidado } \\
\text { Teorias e técnicas } \\
\text { pedagógicas }\end{array}$ & 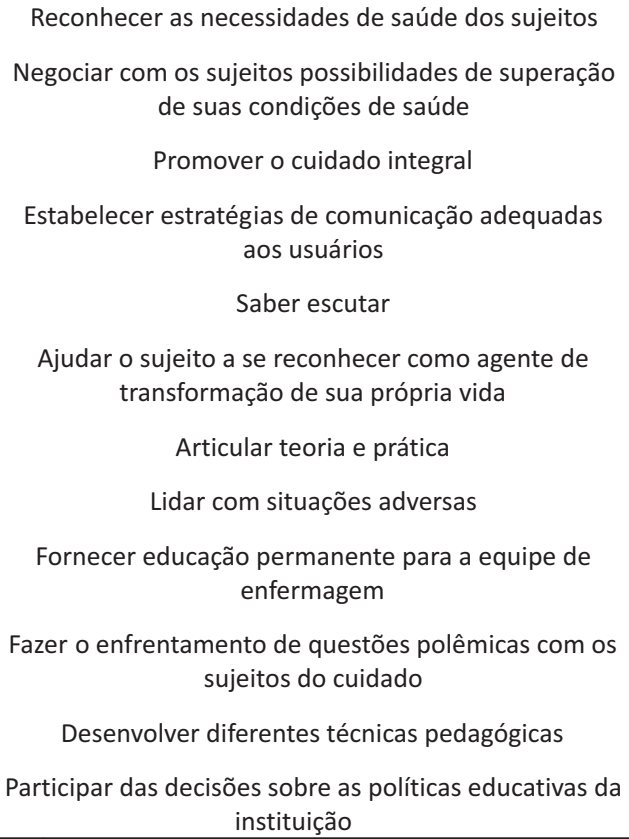 & $\begin{array}{c}\text { Buscar sua educação permanente } \\
\text { Reconhecer seus erros } \\
\text { Envolver-se com pesquisa } \\
\text { científica } \\
\text { Dedicar-se ao trabalho, } \\
\text { discernindo vida pessoal e vida } \\
\text { profissional } \\
\text { Valorizar seus conhecimentos } \\
\text { Reconhecer as limitações do } \\
\text { saber profissional } \\
\text { Gostar do trabalho que faz } \\
\text { Responsabilizar-se pela ação } \\
\text { educativa } \\
\text { Ter paciência com os usuários e } \\
\text { seus familiares } \\
\text { Transmitir segurança } \\
\text { Envolver-se no cuidado }\end{array}$ & $\begin{array}{c}\text { Valorizar o conhecimento } \\
\text { dos sujeitos } \\
\text { Trabalhar em equipe } \\
\text { Respeitar e compreender } \\
\text { o ser humano } \\
\text { Ter postura flexível, } \\
\text { aberta e sem } \\
\text { preconceitos } \\
\text { Colocar-se como parceira } \\
\text { no processo educativo }\end{array}$ \\
\hline
\end{tabular}

Quadro 4 - Conhecimentos, habilidades e atitudes para a ação educativa da enfermeira na perspectiva dos gestores do HU e CSE - São Paulo - 2007

\begin{tabular}{|c|c|c|c|}
\hline Saber conhecer & Saber fazer & Saber ser & Saber conviver \\
\hline $\begin{array}{l}\text { Ter uma visão ampla de } \\
\text { mundo e de políticas de saúde } \\
\text { Dosar conhecimento técnico e } \\
\text { habilidade relacional } \\
\text { Dominar o conteúdo } \\
\text { específico da ação educativa }\end{array}$ & $\begin{array}{l}\text { Liderar e coordenar a equipe de enfermagem } \\
\text { com perfil democrático } \\
\text { Adaptar a estratégia educativa aos sujeitos } \\
\text { Trabalhar com técnicas grupais } \\
\text { Construir uma dinâmica de trabalho na qual as } \\
\text { responsabilidades sejam compartilhadas } \\
\text { Compreender a representação social que os } \\
\text { usuários têm de sua saúde }\end{array}$ & $\begin{array}{c}\text { Ter compromisso ético } \\
\text { com o cuidado }\end{array}$ & $\begin{array}{l}\text { Lidar com conflitos } \\
\text { Relacionar-se com os sujeitos } \\
\text { Respeitar o ser humano } \\
\text { Reconhecer o outro } \\
\text { Ter uma atitude simétrica em relação aos } \\
\text { sujeitos assistidos, reconhecendo seus } \\
\text { conhecimentos } \\
\text { Compartilhar saberes } \\
\text { Ter postura flexível e aberta }\end{array}$ \\
\hline
\end{tabular}


Quadro 5 - Conhecimentos, habilidades e atitudes para sua ação educativa das enfermeiras na perspectiva dos usuários do HU e CSE - São Paulo - 2007

\begin{tabular}{|c|c|c|c|}
\hline Saber conhecer & Saber fazer & Saber ser & Saber conviver \\
\hline $\begin{array}{l}\text { Ter conhecimento sobre } \\
\text { as diferentes etapas da } \\
\text { vida do ser humano }\end{array}$ & $\begin{array}{c}\text { Ensinar o auto-cuidado } \\
\text { Utilizar estratégias de comunicação adequadas à } \\
\text { capacidade de entendimento dos sujeitos } \\
\text { Informar sobre os recursos disponíveis nos } \\
\text { serviços de saúde } \\
\text { Promover o cuidado integral } \\
\text { Acolher as necessidades de saúde dos sujeitos } \\
\text { Buscar e compartilhar informação técnico- } \\
\text { científica com a equipe de enfermagem }\end{array}$ & $\begin{array}{c}\text { Agir com alegria e descontração } \\
\text { Oferecer atenção e carinho às } \\
\text { pessoas que cuida } \\
\text { Ter paciência com os sujeitos } \\
\text { durante o cuidado } \\
\text { Dedicar-se ao trabalho }\end{array}$ & $\begin{array}{l}\text { Respeitar os sujeitos e sua } \\
\text { autonomia } \\
\text { Trabalhar em equipe } \\
\text { Promover o diálogo com os } \\
\text { sujeitos }\end{array}$ \\
\hline
\end{tabular}

O grupo 5, composto pelos usuários dos serviços estudados, enfocou com maior ênfase as dimensões do saber fazer, do saber ser e do saber conviver, em detrimento da dimensão do saber conhecer.

A análise de todos os quadros revelou as similaridades existentes entre os discursos, que fizeram referência a conhecimentos, habilidades e atitudes necessários para o desenvolvimento de práticas educativas mais dialógicas e partici- pativas, mais próximas, portanto, da perspectiva da Educação Popular em Saúde.

A articulação desses conhecimentos, habilidades e atitudes permitiu elaborar um quadro síntese das competências para a ação educativa da enfermeira, a partir da perspectiva dos sujeitos implicados na formação inicial em Enfermagem. Esse processo resultou na elaboração de dez competências, listadas a seguir.

Quadro 6 - Competências para ação educativa da enfermeira - São Paulo - 2007

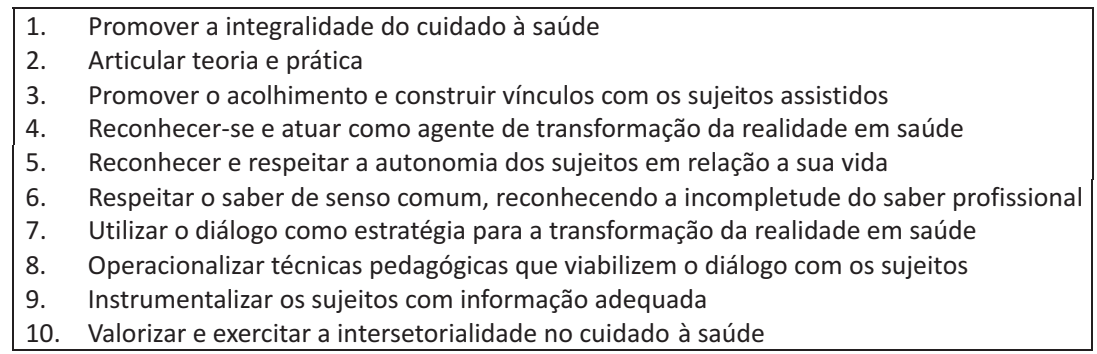

\section{CONSIDERAÇÕES FINAIS}

O percurso metodológico realizado permitiu analisar os dados empíricos captados durante a coleta de dados sem perder as peculiaridades e riqueza dos discursos. A utilização dos quatro pilares da Educação foi fundamental para a organização e recomposição das frases temáticas nos diferentes pilares (conhecer, fazer, ser e conviver). A finalização do processo de construção do perfil de competência só pode ser realizada quando o material empírico recomposto e organizado pelos quatro pilares foi iluminado pelo referencial teórico adotado.
Na perspectiva da Educação Popular, a construção de um perfil de competências para a ação educativa da enfermeira deveria ser feita ouvindo os sujeitos envolvidos no seu processo de trabalho assistencial. Neste sentido, este trabalho, além dos sujeitos tradicionalmente pesquisados (docentes, alunas e enfermeiras), envolveu os gestores dos serviços, que administram e coordenam o trabalho de enfermagem, bem como os usuários, para os quais a assistência de enfermagem é dirigida. Este envolvimento coletivo propiciou a construção de um perfil de competências mais próximo da realidade da prática profissional da enfermeira em sua dimensão educativa e das necessidades dos usuários. 


\section{REFERÊNCIAS}

1. Vasconcelos EM. Educação popular nos Serviços de Saúde. $3^{\mathrm{a}}$ ed. São Paulo: Hucitec; 1997.

2. Vasconcelos EM. Educação popular e a atenção à saúde da família. $2^{\mathrm{a}}$ ed. São Paulo: Hucitec; 2001.

3. Valla VV, Melo JAC. Sem educação ou sem dinheiro? In: Minayo MCS, organizadora. A saúde em estado de choque. $3^{\text {a }}$ ed. Rio de Janeiro: FASE/Espaço e Tempo; 1992. p. 21-35.

4. Freire P. Educação e mudança. Rio de Janeiro: Paz e Terra; 1979.

5. Freire P. Pedagogia do oprimido. $17^{\mathrm{a}}$ ed. Rio de Janeiro: Paz e Terra; 1987.

6. Oliveira MAC. Da intenção ao gesto: a dialética da formação de enfermagem em saúde coletiva [tese livre-docência]. São Paulo: Escola de Enfermagem, Universidade de São Paulo; 2004.

7. Leonello, VM. Competências para ação educativa da enfermeira: uma interface entre o ensino e a assistência de enfermagem [dissertação]. São Paulo: Escola de Enfermagem, Universidade de São Paulo; 2007
8. Perrenoud P. Construir as competências desde a escola. Porto Alegre: Artmed; 1999.

9. Mendes-Gonçalves RB. Tecnologia e organização social das práticas de saúde. São Paulo: Hucitec; 1994.

10. Delors J, organizador. Educação: um tesouro a descobrir. $8^{\mathrm{a}} \mathrm{ed}$. São Paulo: Cortez; 2003. [Relatório para a UNESCO da Comissão Internacional sobre Educação para o Século XXI].

11. Fiorin JF. Elementos da análise de discurso. $9^{\mathrm{a}}$ ed. São Paulo: Contexto; 2000

12. Car MR, Bertolozzi MR. O processo da análise de discurso. In: Chianca TM, Moraes MJA, organizadores. A Classificação Internacional das Práticas de Enfermagem em Saúde Coletiva CIPESC. Brasília: ABEn; 1999. p. 348-55. (Série Didática: Enfermagem no SUS). 